\title{
A Review of Augmented Reality Systems and an Update on The Most Recent Technological Developments and Applications in Dentistry
}

\author{
A. Al-Khaled, I. Al-Khaled, H. Abutayyem
}

\section{ABSTRACT}

This literature review aims to discuss augmented reality systems and provide an update on the most recent technological developments and applications in the dental field. The studies that met the inclusion criteria in the last 20 years, from 2000 to 5 May 2020, in the PubMed database were included. The search resulted in $n=72$ articles, in which $n=40$ included and $n=32$ excluded. AR systems are still being tested as there are still some limitations that limit the adoption of this technology in the dental sector. Several studies have resulted in a device appropriate for clinical use, yet no regular clinical application was recorded.

Keywords: Augmented reality, dentistry, dental field, dental technology.

Published Online: May 10, 2021

ISSN: $2684-4443$

DOI: $10.24018 /$ ejdent.2021.2.3.50

\section{A. Al-Khaled*}

Ras AL-Khimah Medical and Health Sciences University, Ras AL-Khaimah, United Arab Emarites.

(e-mail: alaa.alkaled5@gmail.com)

I. Al-Khaled

Ras AL-Khimah Medical and Health Sciences University, Ras AL-Khaimah, United Arab Emarites.

(e-mail: israa.alkhaled2@gmail.com)

H. Abutayyem

Orthodontic Department, Ras AL-Khimah Medical and Health Sciences University, Ras AL-Khaimah, United Arab Emarites.

(e-mail: huda.abutayyem@rakmhsu.ac.ae)

*Corresponding Author

\section{INTRODUCTION}

Whether in the applied sciences fields, education, military, sports, entertainment industry, medical field, dental field, or others, digital transformation has become omnipresent in a broad spectrum of business sectors [1]-[3]. This transformation has been introduced to dentistry in different shapes, two of which are Augmented Reality (AR), a technology that combines computer-generated images, audios, and videos on a screen with real-life scenes, and Virtual Reality (VR), a synthetic environment, composed of computer-generated images, audios, and videos were the users are emerged inside the artificial environment and cannot see the real world [1], [2], [4]. For the development of AR systems, computerized virtual components or elements are required. AR technology allows users to superimpose virtual content on the physical world; as a result, rather than being a complete substitute, it supplements reality with virtual content as a mix [2], [5]. AR is much easier to comprehend and understand than VR because of this distinguishing feature [6]. Some developers believe that using both AR and VR in certain systems could further enhance the benefits gained from the system [1].

The journey toward the development of AR commenced in 1962 when the first 3D immersive simulator (Sensorama) was developed by Morton Heilig; wish was able to provide multiple sensory impressions like audio, smell, and hepatic stimuli. Then in 1965, Ivan Suntherland developed the Ultimate Display, which provided the sensory impressions that Sensorama provided; but added interactive graphics [7], [8]. Soon after, in 1968, Philico created the first Head Mounted Display (HMD). The spike of creativity continued reaching The University of North Carolina, creating GROPE in the 1970s, then to The US Air Force, leading to the creation of the first flight simulator, Visually Coupled Airborne system Simulator (VCASS) in 1982. Soon after, the VPL company introduced The Data Glove with sensors, which can evaluate and measure the finger's orientation and position, flexion, and identify hand gestures in 1985. Then in 1998, the VPL company also introduced EyePhone, an HMD system that emerges the users in the virtual world. By the end of this decade, Fake Space Labs made Binocular Omni Orientational Monitor (BOOM), a convoluted system that offers a more stable image and increases the sensory responses to movement more than HMD. Due to the development of both BOOM and DataGlove, The National Aeronautics and Space Administration (NASA) developed the Virtual Wind Tunnel, which allows manipulation of the airflow in a virtual space ship or airplane [7].

Following, in 1991, the AR was introduced as a concept by Tom Caudell, and the first AR system prototype was created by the Boing Corporation [7]-[9]. Later in the preceding year, 
in 1992, the University of Illinois, Electronic visualization Laboratories Department, developed a virtual automatic environment called CAVE. This system presents an immersive type of VR system that requires three projectors to display the image on three or more walls. Then, in 1993, an Augmented Reality Global Positioning based System (AR GPS) was developed by Loomis and colleagues for assisting people with visual impairment or blind people in navigation by adding spatial audio information. Moreover, in the same year, Julie Martin developed Dancing in Cyberspace, which represents an $\mathrm{AR}$ theatre that allows actors to interact with virtual objects in real-time [7]. In 1997, Azuma described the difference between AR and VR, proposing that AR varies from VR in three main points, the combination of reality with virtual reality, real-time interactivity with the displayed images, and registry in three dimensions [9]. Also, in the same year, a system called MARS (Mobile AR System) was developed, which can add virtual information about tourist attractions [7].

Moving to the twentieth century, the researches and achievements of AR kept on prospering. In 2000, Thomas et al. developed ARQuake, which is a mobile AR video game. Later in 2008, Wikitude was developed. It presents a technology capable of adding information about the user's environment through the mobile camera, internet, and GPS. In 2009, more AR applications were developed, like AR ToolKit and SiteLens, which can add virtual information to the physical user's surroundings. Also, in 2011, D'Fusion was developed by Total Immersion, which is an AR system for project designing. Lastly, reaching to the development of Google Glass and Microsoft HoloLens in 2013 and 2015, respectively [7]. Following this period, the advancements in this field rapidly accelerated, and multiple companies and corporations have invested in developing AR and VR technologies, like Sony, Samsung, HTC, Google, and others [7].

Multiple components are needed for the development of augmented reality systems. First is a camera, a sensor, or a scanning system that can record real-world scenes and objects. A computer unit is the second part, where the captured images and movements are processed, including analyzing position, tilt, acceleration, and adding depth to the captured images. As a result, 3D images are created. The third component is a display system that allows virtual and 3D objects to be viewed in the real world. Finally, a tracking system is required to complete the registration phase, which involves a constant tracking of the user during the procedure to allow for real-time visualization [10], [11]. Marker-free registration, such as laser skin surface scanning, and markerbased registration, such as anatomical landmarks, bone screws, and skin adhesive markers, are the two primary forms of registration techniques [12], [13].

From a dental perspective, the patient's pre-operative $\mathrm{X}$ rays represent the previously taken photos that were used to create the 3D images. These $\mathrm{x}$-rays can be obtained from $3 \mathrm{D}$ $\mathrm{X}$-rays, such as computed tomography (CT), or from a series of 2D images [8], [14]. CBCT, Laser scanner, Structured light scanner, and Sterophotogrammtry are the four major types of 3D imaging devices used to capture dental and oro-facial structures [11], [15]. After the images were collected and analyzed, they are superimposed on the operating field (patient mouth or face) to provide intra-operative navigational assistance from the pre-operative X-rays taken directly on the patient. This can take the form of a videobased display, a see-through display, or a projection-based AR system. Endoscopic cameras or head-mounted displays (HMD) are used in the video-based display to superimpose virtual objects on a (stereo) video stream, enhancing the viewer's perception of depth, motion, and stereo parallax. In see-through display and projection-based AR, Virtual objects are projected on transparent silver mirrors, see-through devices, and projectors. The virtual objects are projected on a device positioned between the patient and the operator in the operating area [10], [12], [16]-[20]. 3D image display technologies vary; among them, we have stereoscopy, integral imaging (or integral photography), and holography. Stereoscopy generates depth perception through two images; that resemble the left and right images seen by the human visual systems. Nonetheless, stereoscopy has limited data bandwidth, as it is only capable of using two images only. Holography has an enormous data bandwidth, making it difficult to be handled in real-time, and provide satisfactory viewing angles and resolution. Holography also requires expensive and complicated devices for the generation of 3D images; due to that, its usage and application are limited. Integral imaging does balance both of the previously mentioned technologies, as it has medium data bandwidth. The required devices consist of a high-resolution liquid crystal display (LCD) and a lens array for the 3D image display. The resulting image can be observed without the use of special devices or glasses. Due to the previously mentioned features, multiple studies covered integral imaging technology [21]-[23].

In AR Systems, the virtual objects can be viewed from multiple angles and follow the patient and the operator's movements using tracking systems [10], [19]. Tracking is accomplished using two methods. The first method utilizes Fiducial Markers, which are based on anatomical landmarks derived from X-rays. Surface Matching is the second method, which relies on position sensors on both the instrument and the patient. Tracking devices are used to monitor the patient movements, instruments, and the operator, then pass the collected data to the processing unit for visualization in almost real-time. If any of the elements being tracked moves, the process of registration and re-registration takes time and depends upon the speed of the processing unit [11], [19]. The sophistication of AR technology has delayed its introduction and implied the need for a less complicated technology, and that is VR [6].

Dental scanner usage is organized in a 3-step process. First, obtaining the digital object by a scanning device, modifications are made digitally, then the updated data is moved back to a solid-state. Augmented reality enables direct visualization; thus, it aids in bypassing the last transitional step and prevents data and time loss on a wide scale. The ability to visualize digital content on the patient increases the possibility of achieving a better result in digital procedures [8]. The reason why this literature review focuses on augmented reality systems and provide an update on the most recent technological developments and applications in the dental field. 


\section{MethodOlOGY}

This literature review was approved by RAK Medical and Health Sciences University ethical committee and institutional review board. It covered the PubMed database, from the year 2000 - 5 May 2020, for the most recent technological developments and applications in the dental field. The search terms "Augmented reality" AND "Dentistry" were used. The search resulted in n=72 articles, in which $\mathrm{n}=40$ included and $\mathrm{n}=32$ excluded. Article's selection was done in two stages: first, title and abstract evaluation, resulting in the exclusion of $n=19$ articles, leaving $\mathrm{n}=53$. Then a complete article evaluation, which resulted in the exclusion of $n=13$, leaving $n=40$ (Fig. 1). The following is a list of the papers that are included in (Table I). Since the previous articles did not meet the inclusion requirements, the included articles in Table 1 are listed in chronological order and begin in 2005. All studies published in a language other than English, as well as editorials, letters to the editor, animal experiments, short communications, Cranial-Maxillofacial Surgery studies, and articles that do not present an application or use of AR systems in dentistry, were excluded. Studies focusing on other technological advancements that alter the normal visual environment, such as mixed reality, hybrid reality, and virtual reality, were also excluded from the study.

\section{RESULT}

Computer technology with 3-dimensional virtual planning has introduced new concepts to pre-operative assessments and treatment planning. The clinical application of those systems has led to an increase in the quality of treatment and patient satisfaction [10], [13], [14], [24]-[26]. Multiple systems and methods have been covered for the implication of AR in clinical practices. The reason is that no standard method for AR technology application in clinical practice has been yet proposed [5], [17]. This encouraged the researcher's to either use the already present systems with modifications [16], [18], [27], [28] or to create new systems that would provide better outcomes [5], [25], [29], [30]. Dental applications of augmented reality systems in the literature were divided according to dental specialties and treatment used (Table II). The systems used in clinical settings are marked with (*) in (Table II). These systems have been further described below.

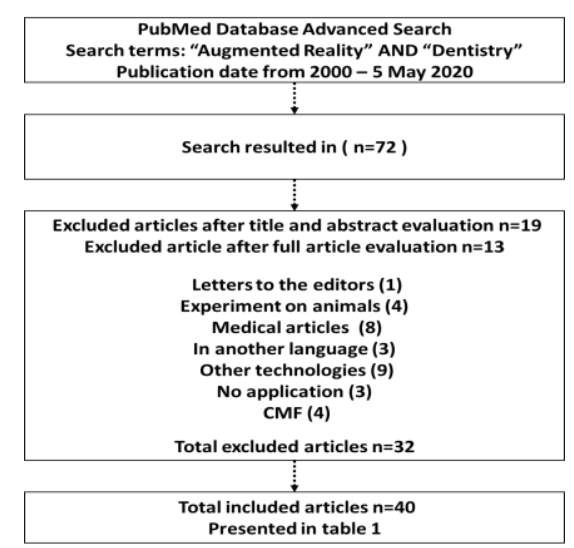

Fig. 1. Flowchart of the method of data collection.

\section{Microscopic-ASSIST GUIDED INTERVENTION (MAGI)}

An augmented reality system, developed at Kings College London, called Microscopic-assist guided intervention (MAGI), has been used to outline the extent of lesions associated with the mandible and maxilla. The system depends on the projection of images through the binocular optics of a tracked and accurately calibrated surgical microscope. For validity check, the system experimented in a clinical setting on a 45-year old female volunteer. She presented to the Hospital with a poorly differentiated squamous cell carcinoma of the right maxilla. A right hemimaxillectomy and reconstruction were planned. MAGI system was used to provide navigational support by projecting a 3-dimensional representation of lesions on the operating field (Fig. 2), which aided in outlining the extent of the tumor around the maxillary and pterygoid regions. For proper alignment of the projected image with the patient's anatomy, the researcher used a10 fiducial markers accommodated on a splint. The splint was built so it would be visible on CT and PET scans; so, when taking the preoperative scans, the splint was accurately fitted to the maxilla (Fig. 2); this allowed for the proper anatomical and functional display of the tumor and the adjacent tissues, aiding in the demarcation of the extent of the lesion. Upon usage, the system showed an accuracy of about $1 \mathrm{~mm}$. The histopathological examination results confirmed that the tumor had was completely excised [19].
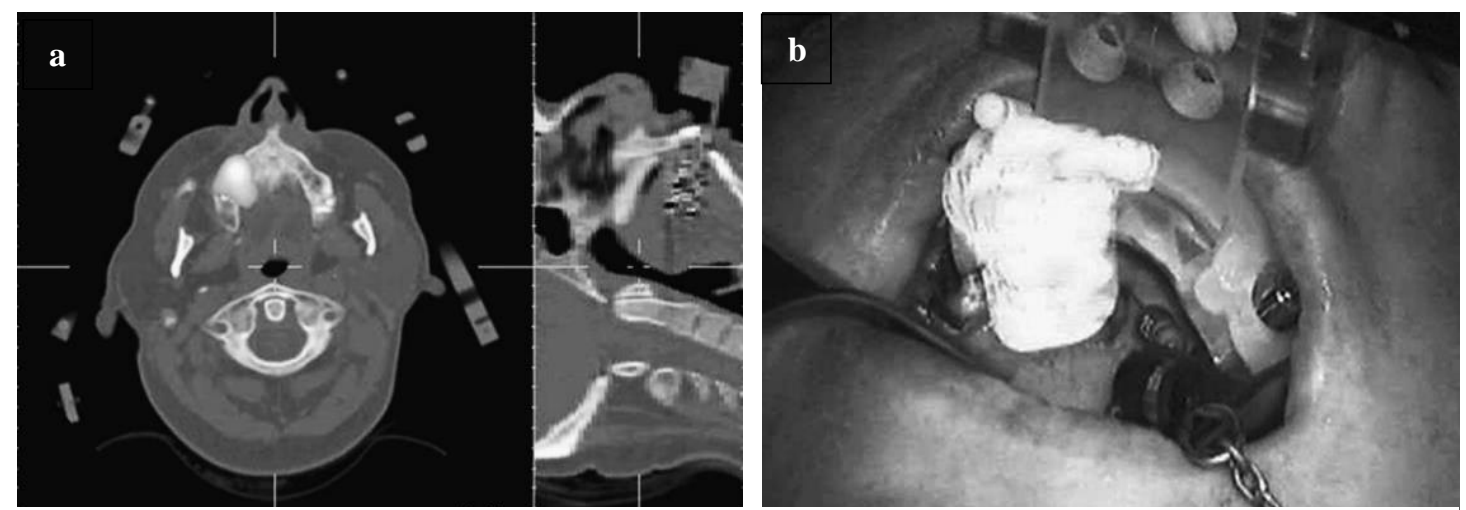

Fig. 2. Display of colocalised CT and PET images (a). Augmented reality stereo overlay of the tumour seen through the modified surgical microscope of MAGI.CT and PET images (b). 


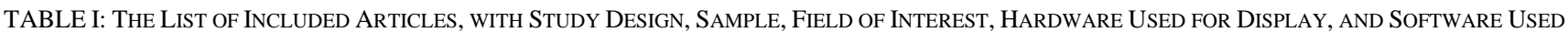

\begin{tabular}{|c|c|c|c|c|c|}
\hline \multicolumn{6}{|c|}{ FOR PROCESSING } \\
\hline Author & Year & Study Design & Sample & $\begin{array}{l}\text { Human/ } \\
\text { Phantom }\end{array}$ & Field of interest \\
\hline Nijmeh A.D. & 2005 & Review & Review & Review & Surgery \\
\hline Mischkowski R.A. & 2006 & Clinical trail & 5 & Humans & Surgery \\
\hline Tran H.H. & 2011 & $\begin{array}{c}\text { Experimental study on } \\
\text { a phantom and a } \\
\text { feasibility study on a } \\
\text { volunteer }\end{array}$ & 1 Phantom/ 1 Volunteer & Both & Surgery \\
\hline Zhu M. & 2011 & Clinical trail & 15 & Humans & Surgery \\
\hline Aichert A. & 2012 & Clinical trail & 3 & Humans & Orthodontics \\
\hline Bruellmann D.D & 2013 & $\begin{array}{l}\text { Experimental in vitro } \\
\text { study }\end{array}$ & 126 Human Teeth & Human teeth in vitro & Endodontics \\
\hline Suenaga $\mathrm{H}$. & 2013 & Pilot study & 1 Phantom/ 1Volunteer & Both & Surgery \\
\hline Zinsera M.J. & 2013 & Clinical trail & 16 & Humans & Surgery \\
\hline Wang J. & 2014 & $\begin{array}{l}\text { Experimental study on } \\
\text { a phantom }\end{array}$ & 1 & Phantom & Surgery \\
\hline Badiali G. & 2014 & $\begin{array}{l}\text { Experimental study on } \\
\text { a phantom }\end{array}$ & 1 & Phantom & Surgery \\
\hline Lin Y.K & 2015 & $\begin{array}{l}\text { Experimental study on } \\
\text { a phantom }\end{array}$ & $\begin{array}{c}40 \text { Osteotomy Sites on } \\
4 \text { Maxilla and } 4 \\
\text { Mandible } \\
\text { Stereolithographic } \\
\text { Models }\end{array}$ & Phantom & Surgery \\
\hline Espejo-Trung L.C & 2015 & $\begin{array}{l}\text { Qusitionnaire-based } \\
\text { Clinical trail }\end{array}$ & 77 & Resin Teeth & Educational \\
\hline Suenaga $\mathrm{H}$. & 2015 & Pilot study & 1 Phantom/ 1Volunteer & Both & Surgery \\
\hline Albuha Al-Mussawi R. & 2016 & Review & Review & Review & Review \\
\hline Zhu M. & 2017 & $\begin{array}{l}\text { Experimental study on } \\
\text { a phantom }\end{array}$ & $\begin{array}{c}20 \text { Stereolithographic } \\
\text { Models }\end{array}$ & Phantom & Surgery \\
\hline Won Y.J & 2017 & Clinical trail & 1 & Human & Educational \\
\hline Wang J. & 2017 & $\begin{array}{c}\text { Experimental study on } \\
\text { a phantom and a } \\
\text { feasibility study on a } \\
\text { volunteer }\end{array}$ & 1 Phantom/ 1Volunteer & Both & Surgery \\
\hline Llena C. & 2018 & $\begin{array}{l}\text { Qusitionnaire-based } \\
\text { Study }\end{array}$ & $\begin{array}{l}41 \text { Student Devided } \\
\text { into two groups }\end{array}$ & Models & Educational \\
\hline Huang T.K. & 2018 & Review & Review & Review & Review \\
\hline Murugesan Y.P. & 2018 & Experimental Study & 6 Groups & Humans & Surgery \\
\hline Zhu M. & 2018 & Clinical trail & $\begin{array}{l}93 \text { patients, divided } \\
\text { into three comparison } \\
\text { groups. }\end{array}$ & Humans & Surgery \\
\hline Kwon H.B. & 2018 & Review & Review & Review & Review \\
\hline Jiang W. & 2018 & Clinical trail & $\begin{array}{l}12 \text { RP Mandibular } \\
\text { Models }\end{array}$ & Models & Surgery \\
\hline Basnet B.R. & 2018 & Experimental Study & 10 Groups & Humans & Surgery \\
\hline Goodacre C.J. & 2018 & Perspective Study & Not presented & Not presented & Educational \\
\hline Ma L. & 2019 & $\begin{array}{l}\text { Experimental study on } \\
\text { a phantom and a } \\
\text { feasibility study on a } \\
\text { volunteer }\end{array}$ & 5 Phantom/ 1 Volunteer & Both & Surgery \\
\hline Bosc R. & 2019 & Review & Review & Review & Surgery \\
\hline Mladenovic R. & 2019 & Prospective Study & $\begin{array}{l}41 \text { Student Divided into } \\
\text { two groups }\end{array}$ & Models & Educational \\
\hline Touati R. & 2019 & $\begin{array}{l}\text { Questionnaire-based } \\
\text { Pilot Study }\end{array}$ & 18 Student & Humans & Prosthodontics \\
\hline Wang J. & 2019 & $\begin{array}{l}\text { Experimental study on } \\
\text { a phantom and a } \\
\text { feasibility study on a } \\
\text { volunteer }\end{array}$ & 1 Phantom/ 1Volunteer & Both & Surgery \\
\hline Joda T. & 2019 & Review & Review & Review & Review \\
\hline Pietruski P. & 2019 & $\begin{array}{l}\text { Experimental study on } \\
\text { a phantom. }\end{array}$ & $\begin{array}{c}126 \text { osteotomies were } \\
\text { performed on } 21 \\
\text { identical mandible } \\
\text { models }\end{array}$ & Phantom & Surgery \\
\hline Farronato M. & 2019 & Review & Review & Review & Review \\
\hline Pellegrino G. & 2019 & Clinical trail & 2 & Humans & Surgery \\
\hline Kim-Berman H. & 2019 & $\begin{array}{l}\text { Questionnaire-based } \\
\text { Experimental Study }\end{array}$ & 93 Student & Not presented & Educational \\
\hline Ayoub A. & 2019 & Review & Review & Review & Surgery \\
\hline Zhou Y. & 2019 & Pilot Study & $\begin{array}{l}\text { Extracted human teeth } \\
\text { installed on model }\end{array}$ & Not presented & Operative \\
\hline Amantini S. & 2020 & $\begin{array}{l}\text { Questionnaire-based } \\
\text { prospective Study }\end{array}$ & Not presented & Not presented & Educational \\
\hline Mladenovic R. & 2020 & Prospective Study & 21 Student & Humans & Educational \\
\hline Zafar S. & 2020 & $\begin{array}{l}\text { Questionnaire-based } \\
\text { Study }\end{array}$ & 88 Student & Humans & Educational \\
\hline
\end{tabular}


TABLE II: THE LIST OF SYSTEMS/DEVICES USED ACCORDING TO THE DENTAL SPECIALTIES

\begin{tabular}{|c|c|c|}
\hline Dental Specialty & Treatment/Application & Systems/Devices \\
\hline \multirow{10}{*}{ Surgery } & $\begin{array}{c}\text { Outlining the extent of a poorly differentiated squamous } \\
\text { cell carcinoma }\end{array}$ & Microscopic-assist guided intervention (MAGI).* \\
\hline & $\begin{array}{l}\text { Secondary reconstruction of post-traumatic deformities of } \\
\text { the zygoma }\end{array}$ & Head Mounted Display system (ARTMA Biomedical Inc.).* \\
\hline & LeFort 1 Osteotomy procedure & "wearable augmented reality for medicine" WARM. \\
\hline & Implant placement & Sony HMZ-T1 personal 3D viewer. \\
\hline & Implant placement & Microsoft HoloLens. \\
\hline & Maxillary positioning & X-Scope.* \\
\hline & Bimaxillary osteotomy & I-plan CMF Software.* \\
\hline & Implant placement & $\begin{array}{l}\text { 3D integral imaging technique with usage of half silver } \\
\text { mirror. }\end{array}$ \\
\hline & Mandibular angle oblique split osteotomy (MASO) & ARToolKit software.* \\
\hline & Navigational guide for surgeons & Video see-through AR system for OMFS. \\
\hline Orthodontics & Brackets placement & Light-weight monocular video see-through AR system.* \\
\hline Endodontics & Detection of root canals & C++, Qt, Optimized video system for AR. \\
\hline Prosthodontics & $\begin{array}{l}\text { Educational tool to explain to the patient the different } \\
\text { smile possibilities }\end{array}$ & IvoSmile Kapanu, Ivoclar-Vivadent. \\
\hline Restorative & Detecting early dental decay and monitoring & $\begin{array}{l}\text { Magic Leap One AR HMD. } \\
\text { serious game (immersive virtual environment using AR), An }\end{array}$ \\
\hline Peadodontics & Oral hygiene education for children & $\begin{array}{l}\text { interactive interface, Kinect for Windows SDK } 2.0 \\
\text { (Microsoft Corp). }\end{array}$ \\
\hline
\end{tabular}

* Indicates the Systems that have been used in clinical settings.

\section{HEAD MOUNTED DisPlay SYSTEM (ARTMA BIOMEDICAL INC.)}

Head-Mounted Display system developed by ARTMA Biomedical Inc. is another AR-based system usually used in minimally invasive surgeries to project the necessary data directly to the view of the surgeon, where the anatomical structures of the patient are directly overlapped on the operating field. This system has been used multiple times for osteotomies, localization of foreign bodies, oral implant operation, and to navigate instruments during particular procedures like osteosarcoma operations in the deep infraorbital region or to guide the oscillating saw in orthognathic operations by superimposing virtual osteotomy lines. Clinically the system was used in a secondary reconstruction of post-traumatic deformities of the zygoma and showed satisfactory results. The procedure was planned using CT scans. Graphic lines were drawn at the level of the zygomatic arch on scans; to help in the identification of the outer surface of the bone. The 3-dimensional shape, which was projected intraoperatively on the surgeon's HMD and a computer station, was developed from a mirror image of the healthy side to have an aesthetic result [19].

\section{X-SCOPE}

$\mathrm{X}$-Scope is an AR tool developed by BrainLab company based in Heimstetten, Germany, in cooperation with Vector Vision Company. X-Scope allows the optical analysis of superimposed 3D virtual images developed from pre- operative CT or MRI scan with anatomical structures; hence, its usage is possible in navigated translocation of bony segments. This tool includes a portable, specially, adapted high-resolution liquid crystal display (LCD) screen with an attached reference star and a digital camera (Fig. 3). A feasibility study done by Mischkowski, R. A. et al. in 2006 covered the use of X-Scope to control the translocation of maxillary bony segments after Le Fort I osteotomy within a bi-maxillary procedure for five female patients in orthognathic surgery. All patients had Angels class III malocclusion. Cephalometric X-rays and CT scans were obtained pre-operatively for surgical planning. During the surgery, the virtual image of the maxilla was displayed on the patient's picture on an LCD portable screen. The orientation of the screen was tracked wirelessly by the navigational system and then matched with the pre-operatively acquired patient data allowing real-time navigation while moving the LCD Screen (Fig. 4). The final position of the maxilla was believed to be right when tooth surfaces, the observed bone surface, and the multi-band archwire were maximally immersed in the 3D visual image (Fig. 4). For proper alignment of the maxilla, the usage of inter-maxillary occlusal splints was necessary. Then, for the accuracy test, Pre-operative and post-operative Cephalometric scans were required. The results showed no breakdowns of the system nor technical failures. However, one hour was needed for the pre-operative registration process. Technical issues that resulted in the extra time required may be reduced with the increase in the operator experience with the software [25].
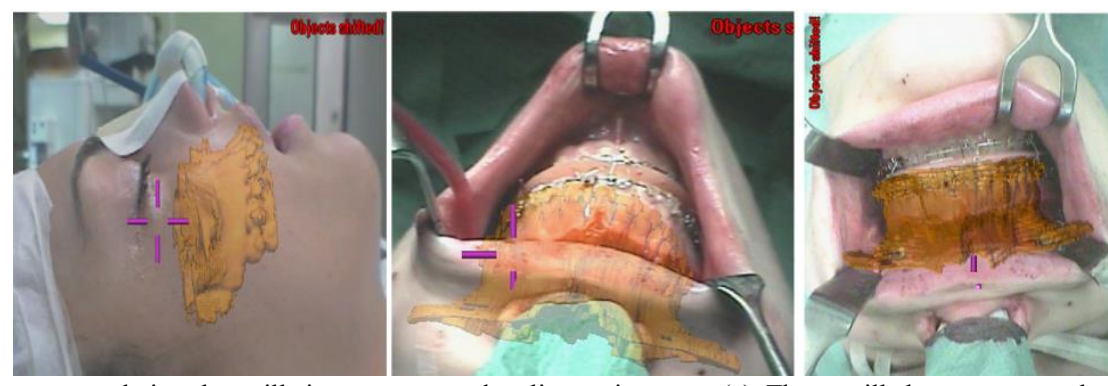

Fig. 4. Surgeon's view of the segmented virtual maxilla in an augmented reality environment (a). The maxilla has not yet reached the planned position (b). Maximal submersion of the virtual maxilla in the real object - the final position has been accomplished (c). 


\section{I-PLAN CMF SOFTWARE}

Zinser M. J. et al. in 2013, used I-plan CMF Software (BrainLab). According to this study, a 3-phase approach was used to do the virtual planning, including anthropometric and cephalometric analyses, the definition of planes of symmetry, and virtual orthognathic planning. To achieve facial symmetry 3- dimensional reference coordinates are needed. The reference plane used is the Frankfort horizontal plane (FHP), as it is not affected by most craniofacial abnormalities. After thoroughly analyzing and constructing the ideal facial symmetry, the translocation of the maxilla can be done virtually by an image-guided visualization display (IGVD) with video graphics array (VGA) camera. Sixteen adult patients, Standard Deviation (SD) age 24, were included. All patients were diagnosed with skeletal class III with an open bite or vertical maxillary extrusion and had a bimaxillary osteotomy. Ten patients had a low Le Fort I osteotomy, and the remaining six had a high Le Fort I osteotomy. Preoperative scans were taken, and post-operative scans were taken six months after the operation. The prominent advantage of using the IGVD system is the ability to augment the virtual images with the patient's maxillary position for the surgeon's perception. This step is crucial for maxillary counter-clockwise rotation as the maxilla can be translocated waverlessly and independently during the procedure; to achieve precise horizontal and vertical leveling concerning the cranial base plane and enables further rotation to the occlusal plane. The IGVD and the navigation unit required additional time to be set up in the operation, adding $60 \mathrm{~min}$ to the overall operating time. There were two technical breakdowns as a result of the movement of the head due to the force applied during down fracturing of the maxilla, forcing the need for the readjustments of the new position of the head, causing the navigational system to slow down. The complete recording was then necessary; the reason why a recommendation to use a head-mounted reference star was proposed for further procedures [31].

\section{ARTOOLKIT SOFTWARE}

The software ARToolKit (ARToolworks, Seattle, WA) is an Augmented Reality Software that can match the 3D images on the real environment immediately after marker recognition. Zhu M. et al. in 2011 used this system on 15 patients who underwent mandibular angle oblique split osteotomy (MASO). CT scans were taken pre-operatively for designing the cutting planes then a Rapid Prototyping (RP) model was printed for splint fabrication. Occlusal splint and marker (OSM) were cemented on the cast (Fig. 5), and a scan was taken. The digital data were imported into the software to generate the $3 \mathrm{D}$ virtual images. The virtual image includes cutting planes, markers, and occlusal splints. As soon as the software recognized the markers, the virtual images were matched, and the image was centered (Fig. 6). The study showed that the ARToolKit can identify the cutting planes planned on the patient's scans and track the patient in realtime, so the virtual image and the marker can move simultaneously. Although one hour was needed for the preoperative registration process, the results showed no breakdowns of the system nor technical failures. Technical issues that resulted in the extra time required might be reduced with the increase in the operator experience with the software [12].

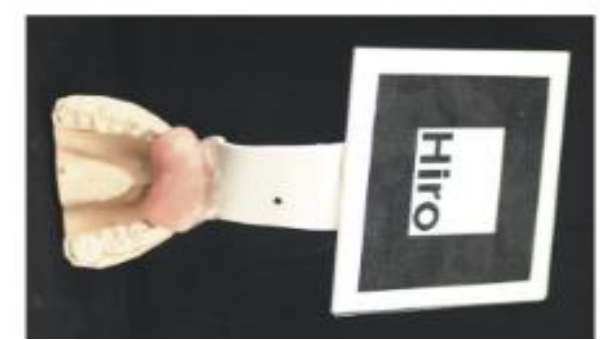

Fig. 5. Occlusal splint with a marker (cemented on a cast).

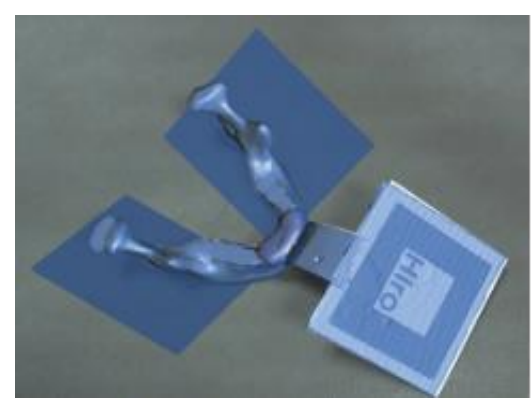

Fig. 6. Overlaying the 3 dimensional virtual image on the real model of the mandible.

In 2017, Zhu M. et al. used the same software with further improvements on the system; to help in locating the Inferior Alveolar Nerve (IAN) for Oral Maxillofacial Surgeries (OMF). The developed system was used on 20 patients, but the study demonstrated only 2 cases. The first case was a male patient with typical hemi-mandibular hyperplasia without condylar hyperplasia. The AR system was used to do a reconstruction of the skull and locate the IAN pre-operatively to decrease surgical complications for the planned osteotomy. After that, the pre-surgical design was generated (Fig. 7), and the AR system presented the osteotomy lines during the procedure for guidance. The second case was a female patient with mandibular angle hypertrophy. A mandibular angle osteotomy was planned. The same procedure was done, and the system presented the correction of the mandibular hypertrophy (Fig. 8). The results showed that the position was correct for both cases, and the motion tracking was highly accurate [13]. In the following year, the system was further improved by the same author [32].
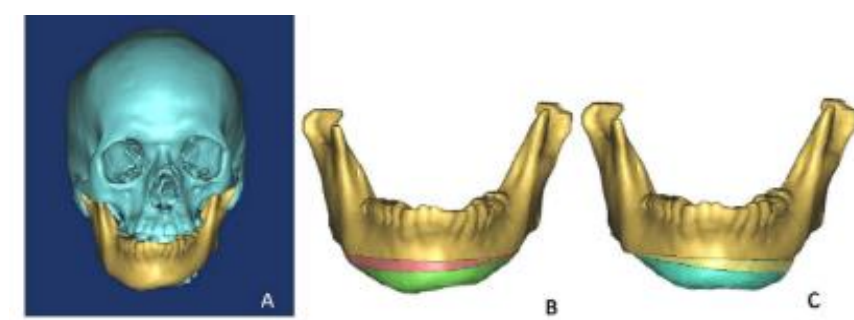

Fig. 7. Surgical plan with the 3D model of bony tissue. (A) 3D model of the patient's skull; (B) two osteotomy lines were drawn to split the deviated mandible into three parts; $(\mathrm{C})$ to ensure a symmetric mandible margin, the intermediate bone section (light yellow) was rotated $180^{\circ}$ and fixed to the upper (golden) and lower parts (blue). 

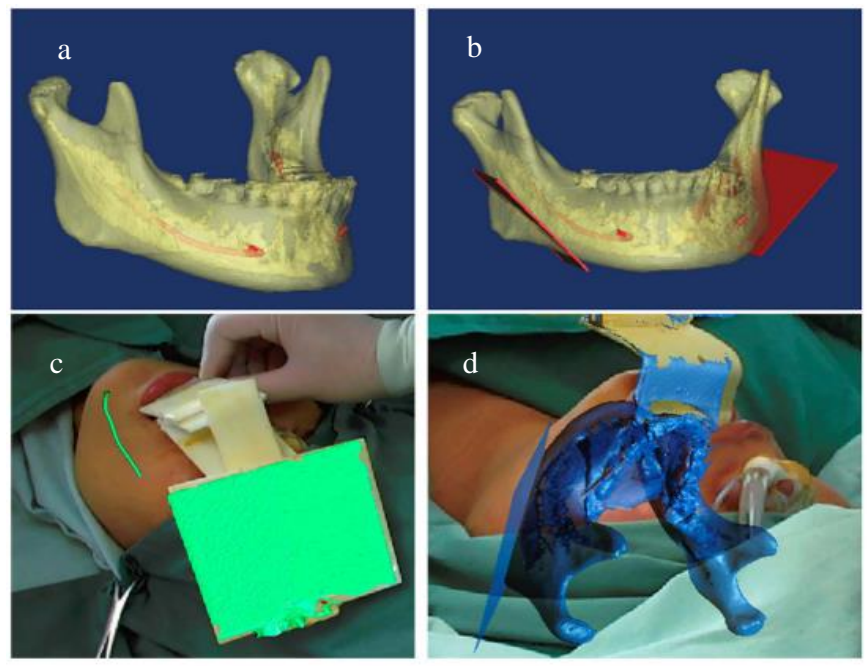

Fig. 8. (a) The IANs were reconstructed using a 3D technique before surgery. (b) osteotomy lines were drawn far from the IANs. (c) the IAN image was displayed on the surgical site. (d) osteotomy lines could be clearly observed during the surgery.

Furthermore, in 2018, Jiang W. et al. proposed using the same system coupled with point cloud-based image-patient registration for implant placements in an edentulous mandible. The study sample was 12 Rapid Prototyping (RP) mandibular models. They were divided into two groups; the first group was treated with the 3D AR system and the other group with the traditional two-dimensional (2D) image guidance. The results showed that using the AR system has decreased the operative time and achieved excellent registration accuracy [27].

\section{Light-Weight MONOCUlaR VIDEO SEE-THROUGH AR SYSTEM}

A study by Aichert A. et al. in 2012 introduced the usage of a Lightweight monocular video see-through AR system to acquire real data on the effectiveness of this system in a real clinical scenario. The system focuses on guiding the orthodontists during brackets placement into individual teeth. This technique allows for the integration of planning and preprocedure simulation. The study was done on three teenage patients. The clinical procedure (brackets placement) was video recorded. The video span was 20 minutes, and it showed the whole procedure and captured it from a camera mounted on the orthodontist's head (Fig. 9). This system requires manual initiation. Also, a proper viewpoint should be chosen for aligning the CT images with the orthodontist's vision. The brackets were cemented individually on the teeth. This system provides a lightweight AR system that avoids excessive, complex, expensive, and full-scale AR medical solutions. It showed a higher efficacy as it reduced chair time, fewer follow-up visits for corrections and readjustment, as well as reduce the probability of relapse [33].

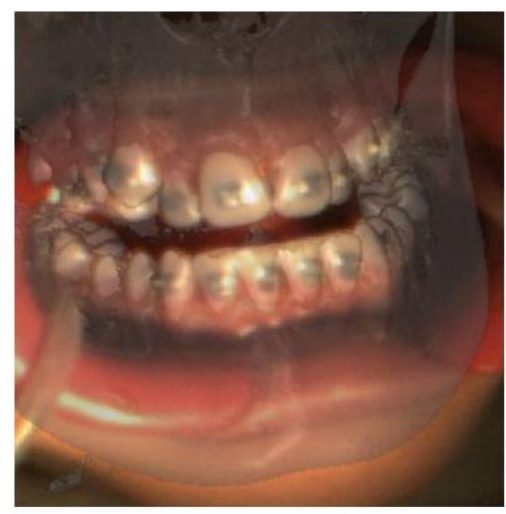

Fig. 9. Video image overlaid.

\section{CONCLUSION}

After reviewing the augmented reality systems, it has been noticed that AR systems are still under testing, as certain drawbacks still tie the spread of this technology in the dental field. Multiple studies have resulted in systems suitable for clinical use, yet no routine clinical application has been reported. Due to the continuous progress in this field, a revolution of the full potential of AR technology will be reviled shortly. Future studies should aim to improve the speed and accuracy of the processing unit, increase the computational power of the computer systems, and create better displays.

\section{ACKNOWLEDGMENT}

We would like to thank all the individuals who contributed to the success of this research. We would like to direct a special thanks to all the faculty, supervisors, and ethical committee in the RAKCODS and RAKMHSU.

\section{REFERENCES}

[1] Huang TK, Yang CH, Hsieh YH, Wang JC, Hung CC. Augmented reality (AR) and virtual reality (VR) applied in dentistry. Vol. 34, Kaohsiung Journal of Medical Sciences. Elsevier (Singapore) Pte Ltd; 2018. p. 243-8.

[2] Kipper G. What Is Augmented Reality? In: Augmented Reality [Internet]. Elsevier; 2013 [cited $2020 \mathrm{Apr} 15]$. p. 1-27. Available from: https://linkinghub.elsevier.com/retrieve/pii/B9781597497336000012

[3] Phuyal S, Bista D, Bista R. Challenges, Opportunities and Future Directions of Smart Manufacturing: A State of Art Review. Sustain Futur [Internet]. 2020 Jan 1 [cited 2020 May 10];2:100023. Available from:

https://linkinghub.elsevier.com/retrieve/pii/S2666188820300162.

[4] Joda T, Gallucci GO, Wismeijer D, Zitzmann NU. Augmented and virtual reality in dental medicine: A systematic review. Comput Biol Med [Internet]. 2019;108(March):93-100. Available from: https://doi.org/10.1016/j.compbiomed.2019.03.012.

[5] Badiali G, Ferrari V, Cutolo F, Freschi C, Caramella D, Bianchi A, et al. Augmented reality as an aid in maxillofacial surgery: Validation of a wearable system allowing maxillary repositioning. J CranioMaxillofacial Surg [Internet]. 2014;42(8):1970-6. Available from: http://dx.doi.org/10.1016/j.jcms.2014.09.001.

[6] Mladenovic R, Dakovic D, Pereira L, Matvijenko V, Mladenovic K. Effect of Augmented Reality simulation on administration of local anesthesia in pediatric patients. Eur J Dent Educ. 2020.

[7] Cipresso P, Giglioli IAC, Raya MA, Riva G. The Past, Present, and Future of Virtual and Augmented Reality Research: A Network and Cluster Analysis of the Literature. Front Psychol [Internet]. 2018 Noy 6 [cited 2020 Apr 30];9(NOV):2086. Available from: https://www.frontiersin.org/article/10.3389/fpsyg.2018.02086/full. 
[8] Farronato M, Maspero C, Lanteri V, Fama A, Ferrati F, Pettenuzzo A, et al. Current state of the art in the use of augmented reality in dentistry: A systematic review of the literature. BMC Oral Health. 2019 Jul $8 ; 19(1)$.

[9] Llena C, Folguera S, Forner L, Rodríguez-Lozano FJ. Implementation of augmented reality in operative dentistry learning. Eur J Dent Educ. 2018;22(1):e122-30

[10] Suenaga H, Hoang Tran H, Liao H, Masamune K, Dohi T, Hoshi K, et al. Real-time in situ three-dimensional integral videography and surgical navigation using augmented reality: a pilot study. Int J Oral Sci [Internet]. 2013 Jun 24 [cited 2020 May 22];5(2):98-102. Available from: http://www.nature.com/articles/ijos201326.

[11] Al-khaled I, Al-khaled A, Abutayyem H. Edelweiss Applied Science and Technology Augmented Reality in Dentistry: Uses and Applications in the Digital Era. 2021;5(1):25-32.

[12] Zhu M, Chai G, Zhang Y, Ma X, Gan J. Registration strategy using occlusal splint based on augmented reality for mandibular angle oblique split osteotomy. J Craniofac Surg. 2011;22(5):1806-9.

[13] Zhu M, Liu F, Chai G, Pan JJ, Jiang T, Lin L, et al. A novel augmented reality system for displaying inferior alveolar nerve bundles in maxillofacial surgery. Sci Rep. 2017 Feb 15;7.

[14] Suenaga H, Tran HH, Liao H, Masamune K, Dohi T, Hoshi K, et al. Vision-based markerless registration using stereo vision and an augmented reality surgical navigation system: a pilot study. BMC Med Imaging [Internet]. 2015 Dec 2 [cited 2020 Jun 3];15(1):51. Available from:

http://bmcmedimaging.biomedcentral.com/articles/10.1186/s12880015-0089-5.

[15] Ayoub A, Pulijala Y. The application of virtual reality and augmented reality in Oral \& Maxillofacial Surgery. BMC Oral Health. 2019 Nov $8 ; 19(1)$.

[16] Tran HH, Suenaga H, Kuwana K, Masamune K, Dohi T, Nakajima S, et al. Augmented reality system for oral surgery using $3 \mathrm{D}$ auto stereoscopic visualization. Lect Notes Comput Sci (including Subser Lect Notes Artif Intell Lect Notes Bioinformatics). 2011;6891 LNCS(PART 1):81-8.

[17] Won Y-J, Kang S-H. Application of augmented reality for inferior alveolar nerve block anesthesia: A technical note. J Dent Anesth Pain Med. 2017;17(2):129.

[18] Murugesan YP, Alsadoon A, Manoranjan P, Prasad PWC. A novel rotational matrix and translation vector algorithm: geometric accuracy for augmented reality in oral and maxillofacial surgeries. Int J Med Robot Comput Assist Surg. 2018;14(3):1-14.

[19] Nijmeh AD, Goodger NM, Hawkes D, Edwards PJ, McGurk M. Imageguided navigation in oral and maxillofacial surgery. $\mathrm{Br} \mathrm{J}$ Oral Maxillofac Surg. 2005;43(4):294-302.

[20] Bosc R, Fitoussi A, Hersant B, Dao TH, Meningaud JP. Intraoperative augmented reality with heads-up displays in maxillofacial surgery: a systematic review of the literature and a classification of relevant technologies. Int J Oral Maxillofac Surg [Internet]. 2019;48(1):132-9. Available from: https://doi.org/10.1016/j.ijom.2018.09.010.

[21] Collier RJ, Burckhardt CB, Lin LH, Sanford RJ. Optical Holography [Internet]. Vol. 43, Journal of Applied Mechanics. Murray Hill, New Jersey: Academic Press, Inc. (London) LTD.; 1976 [cited 2020 Jun 3]. 523-523 p. Available from: https://books.google.ae/books?id=pCmlsUKAU8wC\&printsec=frontc over\&source=gbs_ge_summary_r\&cad=0\#v=onepage $\& q \& \mathrm{f}=\mathrm{false}$.

[22] Lambooij M, Ijsselsteijn W, Fortuin M, Heynderickx I. Visual Discomfort and Visual Fatigue of Stereoscopic Displays: A Review. J Imaging Sci Technol. 2009.

[23] Martínez-Cuenca R, Saavedra G, Martínez-Corral M, Javidi B. Progress in 3-D multiperspective display by integral imaging. Proc IEEE. 2009;97(6):1067-77.

[24] Lin YK, Yau HT, Wang IC, Zheng C, Chung KH. A Novel Dental Implant Guided Surgery Based on Integration of Surgical Template and Augmented Reality. Clin Implant Dent Relat Res. 2015;17(3):543-53.

[25] Mischkowski RA, Zinser MJ, Kübler AC, Krug B, Seifert U, Zöller JE. Application of an augmented reality tool for maxillary positioning in orthognathic surgery - A feasibility study. J Cranio-Maxillofacial Surg. 2006;34(8):478-83.

[26] Kwon HB, Park YS, Han JS. Augmented reality in dentistry: a current perspective. Acta Odontol Scand [Internet]. 2018;76(7):497-503. Available from: https://doi.org/10.1080/00016357.2018.1441437.

[27] Jiang W, Ma L, Zhang B, Fan Y, Qu X, Zhang X, et al. Evaluation of the 3D Augmented Reality-Guided Intraoperative Positioning of Dental Implants in Edentulous Mandibular Models. Int $\mathrm{J}$ Oral Maxillofac Implants. 2018;33(6):1219-28.

[28] Wang J, Suenaga H, Hoshi K, Yang L, Kobayashi E. Augmented Reality Navigation with Automatic Marker-Free Image Registration
Using 3-D Image Overlay for Dental Surgery. Biomed Eng (NY). 2014;61(4):1295-304.

[29] Wang J, Shen Y, Yang S. A practical marker-less image registration method for augmented reality oral and maxillofacial surgery. Int $\mathrm{J}$ Comput Assist Radiol Surg [Internet]. 2019;14(5):763-73. Available from: https://doi.org/10.1007/s11548-019-01921-5.

[30] Ma L, Jiang W, Zhang B, Qu X, Ning G, Zhang X, et al. Augmented reality surgical navigation with accurate CBCT-patient registration for dental implant placement. Med Biol Eng Comput. 2019;57(1):47-57.

[31] Zinser MJ, Mischkowski RA, Dreiseidler T, Thamm OC, Rothamel D, Zöller JE. Computer-assisted orthognathic surgery: Waferless maxillary positioning, versatility, and accuracy of an image-guided visualisation display. $\mathrm{Br} \mathrm{J}$ Oral Maxillofac Surg [Internet]. 2013;51(8):827-33. Available from: http://dx.doi.org/10.1016/j.bjoms.2013.06.014.

[32] Zhu M, Liu F, Zhou C, Lin L, Zhang Y, Chai G, et al. Does intraoperative navigation improve the accuracy of mandibular angle osteotomy: Comparison between augmented reality navigation, individualised templates and free-hand techniques. J Plast Reconstr Aesthetic Surg [Internet]. 2018;71(8):1188-95. Available from: https://doi.org/10.1016/j.bjps.2018.03.018.

[33] Aichert A, Wein W, Ladikos A, Reichl T, Navab N. Image-based tracking of the teeth for orthodontic augmented reality. Lect Notes Comput Sci (including Subser Lect Notes Artif Intell Lect Notes Bioinformatics). 2012;7511 LNCS:601-8. 